\title{
Insights into the Roles of Midazolam in Cancer Therapy
}

\author{
Jinghua Jiao, ${ }^{1,2}$ Yuheng Wang, ${ }^{2}$ Xiaofeng Sun, ${ }^{2}$ and Xiaojing Jiang ${ }^{1}$ \\ ${ }^{1}$ Department of Anesthesiology, The First Affiliated Hospital, China Medical University, Shenyang 110001, China \\ ${ }^{2}$ Department of Anesthesiology, Central Hospital, Shenyang Medical College, Shenyang 110024, China \\ Correspondence should be addressed to Xiaojing Jiang; jiang_sophia@163.com
}

Received 21 March 2017; Revised 15 May 2017; Accepted 28 May 2017; Published 19 June 2017

Academic Editor: Shuang-En Chuang

Copyright ( 2017 Jinghua Jiao et al. This is an open access article distributed under the Creative Commons Attribution License, which permits unrestricted use, distribution, and reproduction in any medium, provided the original work is properly cited.

\begin{abstract}
With its high worldwide mortality and morbidity, cancer has gained increasing attention and novel anticancer drugs have become the focus for cancer research. Recently, studies have shown that most anesthetic agents can influence the activity of tumor cells. Midazolam is a $\gamma$-aminobutyric acid $\mathrm{A}\left(\mathrm{GABA}_{\mathrm{A}}\right)$ receptor agonist, used widely for preoperative sedation and as an adjuvant during neuraxial blockade. Some studies have indicated the potential for midazolam as a novel therapeutic cancer drug; however, the mechanism by which midazolam affects cancer cells needs to be clarified. This systematic review aims to summarize the progress in assessing the molecular mechanism of midazolam as an anticancer agent.
\end{abstract}

\section{Introduction}

Cancer has become the most common disease worldwide and is the leading cause of death [1]. Currently, the primary treatment for a solid tumor is still surgical resection. During surgery, anesthesia and the drugs used may affect the tumor and result in the release of tumor cells into the blood, lymphatic system, bone marrow, and even organs, leading to the formation of micrometastatic lesions, an increased risk of tumor recurrence and metastasis, and ultimately affecting postoperative survival rate $[2,3]$. A number of in vitro studies have confirmed that most anesthetic agents, including midazolam, have substantial antitumor effects [4-6]. To date, a few studies have used various cell lines to determine the mechanism underlying the effect of midazolam on cancer cells. However, this mechanism is multifaceted and the means by which midazolam affects a variety of cancer signaling pathways needs to be clarified. This article reviews the biochemical properties of midazolam, its activity, its antitumor properties, and the possible mechanisms involved. We hope to provide a theoretical basis for the potential clinical application of midazolam as a therapeutic agent for tumors.

\section{Chemistry and Clinical Pharmacology of Midazolam}

The chemical structure of midazolam (dormicum) is 8-chloro-6-(2-fluorophenyl)-1-methyl-4H-imidazo[1,5-a] [1,4]benzodiazepine (Figure 1).

As a benzodiazepine, anticonvulsant drug, midazolam has a rapid onset and short-lasting effect. In addition, midazolam has significant hypnotic, anxiolytic, amnesic, and sedative properties and these occur via modulation of the $\mathrm{GABA}_{\mathrm{A}}$ receptor in the central nervous system $[7,8]$. In the clinical situation, midazolam is the current drug of choice for sedation, including preoperative sedation. For patients undergoing caesarean section under spinal anesthesia, midazolam is effective for the prevention of nausea and vomiting [9] and produces postoperative pain relief [10].

However, midazolam was recently reported to be among the 20 most often utilized medications in cancer patients to be associated with toxic side effects [11]. In addition, it has been shown to have neuronal cytotoxicity and apoptosisinducing activity in hematogenic, ectodermal, mesenchymal, and neuronal cells [12-15]. 


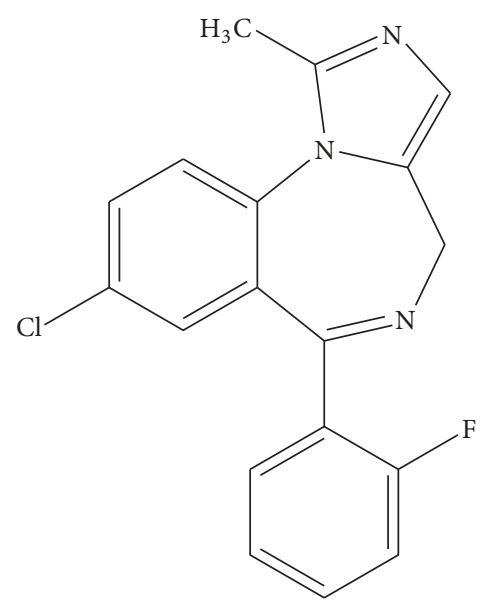

FIgURE 1: The chemical structure of midazolam (dormicum).

\section{Systematic Review}

3.1. Search Strategy. A systematic and comprehensive literature search was performed by two authors (J.J.H. and J.X.J.) independently and using the PubMed, Embase, Web of Science, Ovid evidence-based medicine, Chinese science and technology periodicals (CNKI, VIP, and Wan Fang), and Chinese Biomedical Literature (CBM) databases, for publications up to March 5, 2017. Disagreement between reviewers was resolved by discussion. The following terms were used in each search: cancer, carcinoma, neoplasm, tumor, midazolam, dormicum, and 8-chloro-6-(2-fluorophenyl)-1-methyl-4Himidazo[1,5-a] $[1,4]$ benzodiazepine. The results were limited to English or Chinese language.

3.2. Inclusion and Exclusion Criteria. Any study that clearly stated a link between midazolam and cancer, both in vitro and in vivo, was included. Studies were excluded based on the following criteria: (1) conference abstracts, reviews, conference papers, case reports, editorials, comments, news, congresses, and letters; (2) non-English or Chinese.

3.3. Quality Assessment and Data Extraction. The quality of all eligible studies was assessed by two independent reviewers using the EBLIP Critical Appraisal Checklist [16]. The extracted data from included studies are shown in Table 1.

\section{Results and Discussion}

A total of 822 studies were identified in PubMed, Embase, Web of Science, Ovid evidence-based medicine, Chinese science and technology periodicals (CNKI, VIP, and Wan Fang), and Chinese Biomedical Literature (CBM) using our search strategy. After detailed screening, 12 studies were considered eligible for inclusion in this review (summarized in Figure 2).

4.1. Possible Antitumor Mechanisms of Midazolam In Vitro. There are thirty-three trillion cells in the human body and numerous cellular functions that maintain the balance of these cells. In disease situations, this balance may be disrupted by multiple external stimuli, stress, and the generation of mutant cells [17]. Cell death plays an important role in maintaining cellular balance by removing cells that are "unnecessary" or potentially harmful [18] and may occur via two means, necrosis and apoptosis. Apoptosis is a programmed cell death, whereas necrosis is an "accidental" death resulting from a physical or chemical assault [19]. During the process of necrosis, the cell membrane is distorted and the cell nucleus disintegrates resulting in degradation products. Apoptosis, on the other hand, is a far more regulated process that results in the cell degenerating into contained apoptotic bodies that can be phagocytosed and removed.

4.2. Induction of Apoptosis. Apoptosis plays a crucial role in eliminating cells that are unnecessary or harmful and it also has a role in numerous biological processes, including cell differentiation and proliferation $[20,21]$. With respect to cancer, apoptosis has become a popular target for many treatment strategies as there is a close relationship with apoptosis and many of the processes involved in cancer progression [22-27].

Previous studies using flow cytometry showed that midazolam induced apoptosis in the human lymphoma and neuroblastoma cell lines, MA-10 Leydig tumor cells, and the mantle cell lymphoma cell line, JeKo-1, in a concentrationdependent manner $[12,29,37]$. Potential biomarkers of apoptosis include B cell lymphoma 2 ( $\mathrm{Bcl}-2)$ family proteins, caspase-3, and caspase-9. In the mantle cell lymphoma cell line, JeKo-1, a dose-dependent reduction of Bcl2 , procaspase- 9 and procaspase- 3 protein expression and an increase in cyto- $C$ protein expression were found. The expression of procaspase- 8 protein did not change. It was concluded that midazolam potentially initiates the mitochondrial pathway, not the death receptor pathway, by reducing the expression of $\mathrm{Bcl}-2$, leading in turn to the release of cyto-C in mitochondria. This leads to the activation of caspase 9 and caspase 3 protein and triggers the caspase cascade, ultimately leading to the induction of apoptosis in the JeKo-1 cells [37].

However, in the human lymphoma and neuroblastoma cell lines, Bcl-2 overexpression and caspase 9 deficiency protected against midazolam toxicity, whereas a deficiency in caspase 8 or Fas-associating protein with a novel death domain (FADD) had no effect. Although pancaspase inhibition had a strong protective effect, flumazenil could not inhibit midazolam-induced apoptosis. Midazolam induced apoptosis via activation of the mitochondrial pathway in a concentration-dependent manner. The induction of apoptosis by midazolam is presumably unrelated to $\mathrm{GABA}_{\mathrm{A}}$ receptor pathway signaling [12].

The endoplasmic reticulum stress (ER stress) pathway, also known as the Unfolded Protein Response, is the response of the cell to a dangerous buildup of unfolded or misfolded proteins in the ER [39-41]. C/EBP-homologous protein (CHOP), activating transcription factor 4 (ATF4 ), and phosphorylated $\alpha$ subunit of eukaryotic initiation factor 2 (p-eIF2 $\alpha$ ) are typical ER stress markers [42]. eIF2 $\alpha /$ ATF4/CHOP is an essential signal pathway regulating ER stress [43]. In MA-10 Leydig tumor cells, where apoptosis is induced with midazolam, the overexpression of $\mathrm{p}$-eIF $2 \alpha$, 


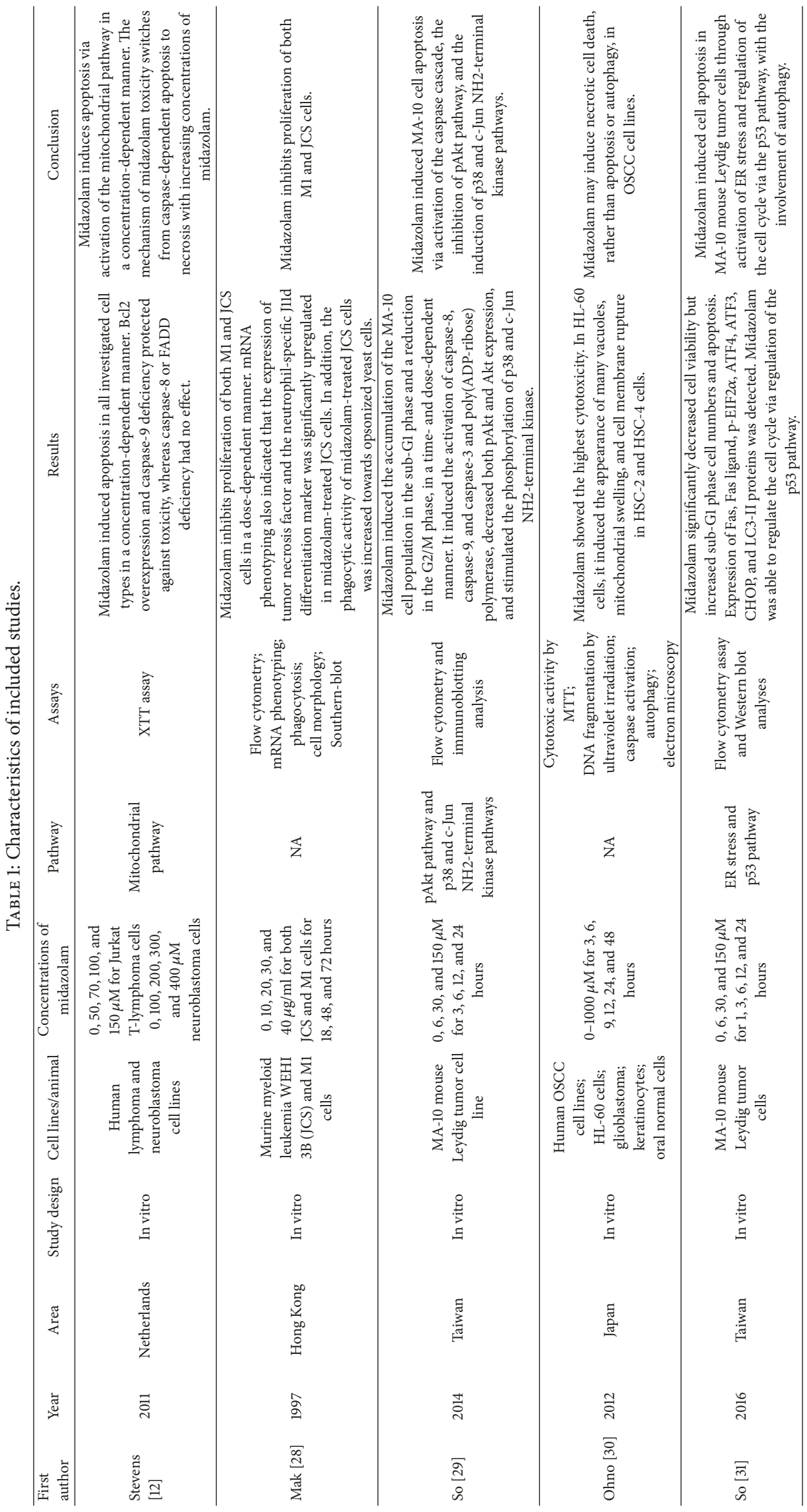




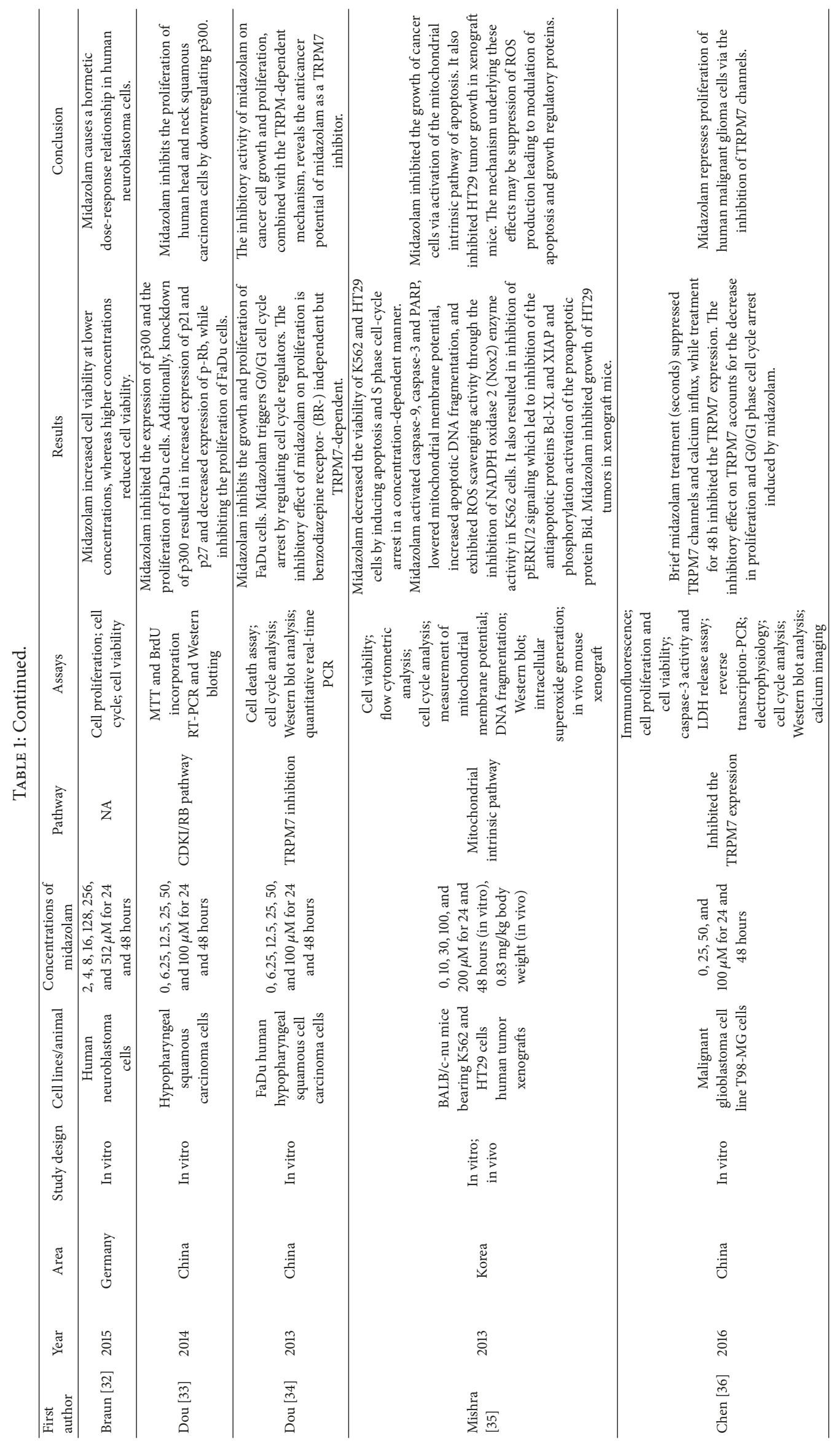




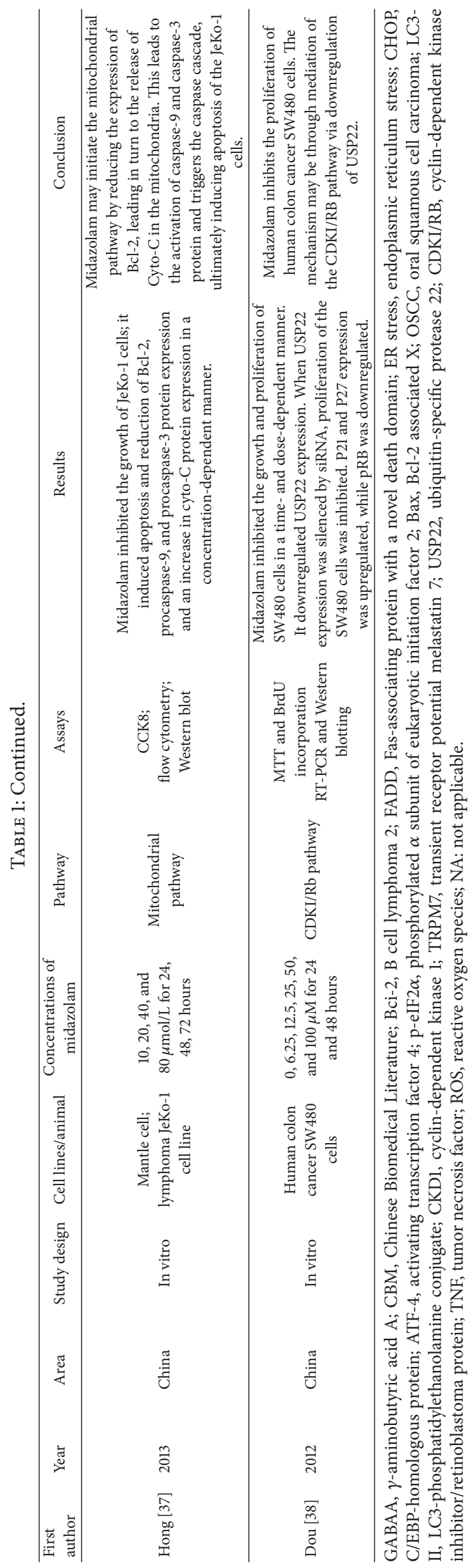




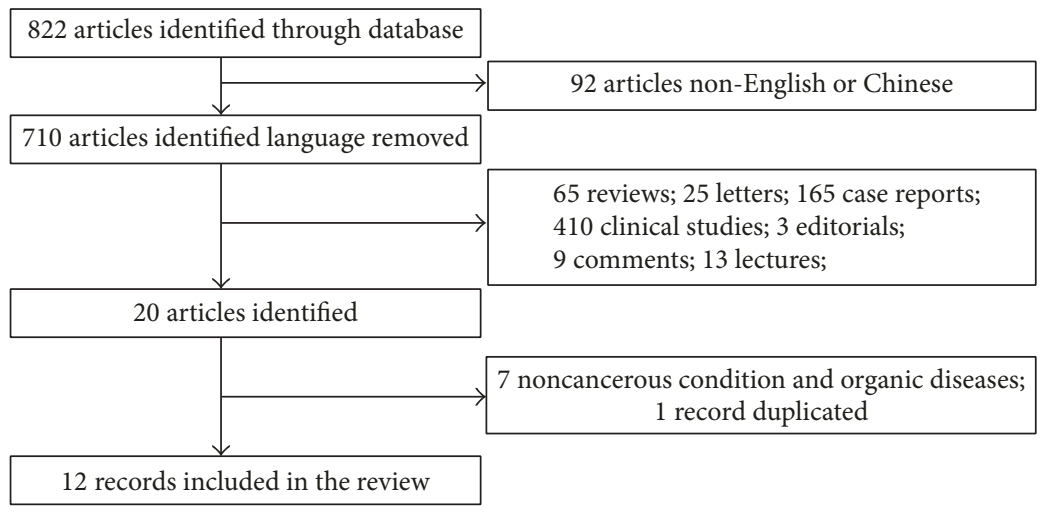

Figure 2: Flow diagram of the studies identification and selection.

ATF4, ATF3, and CHOP was observed, suggesting that midazolam may induce apoptosis via the ER stress pathway [31]. Midazolam was also suggested to induce the activation of caspase- 8 , caspase- 9 , and caspase- 3 and poly(ADP-ribose) polymerase proteins in the mouse Leydig tumor cells. There were no changes in the levels of $\mathrm{Bcl}-2$ associated $\mathrm{X}$ protein (Bax) (a proapoptotic family member) [44], but Bid (also proapoptotic and which is activated by various death stimuli) was significantly decreased after midazolam intervention $[45,46]$. Midazolam decreases the expression of pAkt and Akt and upregulates the phosphorylation of p38 and cJun NH2-terminal kinase, rather than extracellular signalregulated kinases [29]. Thus, midazolam-induced apoptosis may be induced via the activation of the caspase cascade, the inhibition of the pAkt pathway, and the induction of p38 and c-Jun NH2-terminal kinase pathways [29].

4.3. Necrosis. In decreasing order, midazolam showed the greatest toxicity for HL-60 cells, epidermal keratinocytes, oral squamous cell carcinoma (OSCC), and glioblastoma cells. Midazolam did not induce the generation of apoptosis markers in OSCC cells (including DNA cleavage between nucleosomes and activation of caspase-3, caspase-8, and caspase9) but did induce many vacuoles, mitochondrial swelling, and cell membrane rupture [32]. Midazolam cytotoxicity for human lymphoma and neuroblastoma cell lines affected a switch from caspase-dependent apoptosis to necrosis as the concentration increased [12].

4.4. Autophagy. Autophagy is a newly recognized innate defense mechanism that has been observed in cancer and is a physiological program that enables the body to deal with the destruction of cells [47]. Autophagy maintains a homeostatic balance via protein degradation and the turnover of destroyed cellular organelles [48]. Autophagy was not induced with midazolam as midazolam cytotoxicity was not reduced by pretreatment with autophagy inhibitors (3-methyladenine and bafilomycin A1) in the OSCC cell lines [30]. Thus, midazolam appears to induce necrosis, and not apoptosis or autophagy, in OSCC cell lines.

However, in MA-10 cells, the staining and expression of LC3-phosphatidylethanolamine conjugate (LC3-II), which is recruited to autophagosomal membranes, was observed following midazolam treatment, suggesting that midazolam induced autophagy in MA-10 cells [31].

4.5. Effect on the Cell Cycle. The rate of cell proliferation is always determined by cell cycle distribution. There are four phases in the cell cycle including G1, G2, S, and M; G1 and G2 phases are gap phases; $\mathrm{S}$ phase is the synthesis phase during which the genetic material is duplicated; and the $M$ phase is where mitosis partitions the genetic material and the cell divides $[49,50]$. As the genetic material is duplicated in the S phase, the percentage of cells in this phase also reflects the rate of proliferating cells. As the balance between proliferation and apoptosis is destroyed in tumor cells, the percentage of tumor cells in the $S$ phase is much larger than that in normal cells from the same tissues or organs [51].

Another study that looked at the effect of midazolam in mouse Leydig tumor cells showed an accumulation of MA10 cells in the sub- $G_{1}$ phase and a reduction of cells in the $\mathrm{G}_{2} / \mathrm{M}$ phase in a time- and dose-dependent manner [29]. It was suggested that midazolam may inhibit the expression of cyclin-A, cyclin-B, and cyclin-dependent kinase 1 (CDK1) in MA-10 cells and alter the phosphorylation of P21, P27, and p53, thus controlling the cell cycle through the regulation of the p53 pathway [31].

On the other hand, a study by Dou and coworkers showed that midazolam triggered $G_{0} / G_{1}$ cell cycle arrest in the human head and neck squamous carcinoma FaDu cell line by regulating cell cycle regulators [34].

4.6. Inhibition of Proliferation. The human E1A binding protein, p300, also known as EP300 or p300, is encoded by the EP300 gene and regulates the activity of many genes in tissues throughout the body [52]. It plays an essential role in regulating cell growth and division, prompting cells to mature, differentiate, and assume specialized functions, and preventing the growth of cancerous tumors [53]. The p300 protein appears to be critical for normal development before and after birth. The p300 protein carries out its function by activating transcription, the process of translating the genetic blueprint into protein production. Specifically, p300 connects transcription factors and proteins that initiate the 
transcription process with numerous proteins that carry out the transcription process in the cell's nucleus [54].

Midazolam was shown to inhibit the proliferation of FaDu cells, a cell line from a squamous cell carcinoma of the hypopharynx, and attenuated the mRNA and protein levels of p300. The knockdown of p300 resulted in an upregulation of p21 and p27 proteins and downregulation of p-Rb protein. Thus, it appeared that midazolam inhibited the proliferation of $\mathrm{FaDu}$ cells via downregulation of $\mathrm{p} 300$ expression [33].

Similarly, another study on $\mathrm{FaDu}$ cells showed that midazolam was able to inhibit the growth and proliferation of $\mathrm{FaDu}$ cells [34]. However, this study reported that the inhibition of FaDu cell proliferation was mediated by the targeting of transient receptor potential melastatin 7 (TRPM7). TRPM7, which is expressed in human head and neck squamous carcinoma cells, is one of the TRP channel family members. The growth and proliferation of $\mathrm{FaDu}$ cell lines can be inhibited by the inhibition of TRPM7 expression or blocking of TRPM7 channels [55]. Similar results were found in a malignant glioblastoma cell line, T98-MG cell [36].

A further study demonstrated that midazolam inhibited the growth and proliferation of SW480 colonic adenocarcinoma cells in a time- and dose-dependent manner and downregulated ubiquitin-specific protease 22 (USP22) expression. With the use of USP22 small interfering RNA (Si-RNA), they were able to silence USP22 expression and found that SW480 cell proliferation was inhibited, while P21 and P27 expression was upregulated, and pRB downregulated. Thus, a feasible mechanism by which midazolam inhibits proliferation may be via the mediation of cyclin-dependent kinase inhibitor/retinoblastoma protein (CDKI/RB) pathways through the downregulation of USP22 [38].

Midazolam has been shown to inhibit the in vitro growth and differentiation of two murine myeloid leukemia cell lines (WEHI 3B (JCS) and M1 cells) in a dose-dependent manner [28]. Midazolam enhanced the expression of the differentiation antigens Mac-1, F4/80, and Gr-1 in the cells and expression of tumor necrosis factor (TNF-alpha), and the neutrophil-specific J11d differentiation marker was significantly upregulated in midazolam-treated JCS cells.

4.7. Antitumor Effects of Midazolam in Animal Models and Possible Mechanisms. There has only been one animal model study. This was carried out in BALB/c-nu mice bearing K562 and HT29 cell human tumor xenografts. The results showed that midazolam inhibited growth of the cancer cells via activation of the mitochondrial intrinsic pathway of apoptosis and inhibited HT29 tumor growth in the xenograft mice. The mechanism of inhibition of carcinogenesis by midazolam may be a suppression of reactive oxygen species (ROS) production leading to modulation of apoptosis and growth regulatory proteins [35].

\section{Concluding Remarks}

It is interesting to consider the possibility that, besides its use as an anesthetic agent, midazolam may have the ability to prevent or inhibit tumor development. New insights are rapidly being gained into the role of the midazolam in cancer treatment. In this review, the protective role of midazolam in cancer and the potential mechanisms underlying this have been described. Studies suggest a critical role for midazolam in influencing many signaling pathways on which cancer cells death is induced including necrosis and apoptosis. Midazolam can also inhibit the proliferation of cancer by inhibiting cell cycle progression. However, the impact of midazolam on other behavior of tumor cells, such as invasion and metastasis, remains to be further studied.

In relating observations in vitro to molecular events in vivo, a main focus is the different concentrations of midazolam used. In vitro studies, the concentrations of midazolam were usually from 0 to $100 \mu \mathrm{M}$, even achieving $200 \mu \mathrm{M}$ or $1000 \mu \mathrm{M}$. The effect of different concentrations of midazolam on tumor cells was shown in Table 1 . However, only one study has sought to evaluate, in vivo, the effect of midazolam on cancer preventive activities and the concentration of midazolam was $0.83 \mathrm{mg} / \mathrm{kg}$ body weight for BALB/c-nu mice bearing K562 and HT29 cells human tumor xenografts [35]. Further in vivo studies are needed to evaluate the effect of midazolam on cancer preventive activities and even address the relationship between the effective concentrations of midazolam in vivo versus in vitro.

The above discussions on the anticancer activities of midazolam are based mostly on studies with lymphoma cells and Leydig tumor cells. These theories will serve as a basis for researchers to explore the effect of midazolam on other tumors. For example, we are investigating the effect of midazolam on lung cancer cells (A549), and we found that midazolam could induce the apoptosis of A549 cells through regulating signal transducer and activator of transcription 3 (Stat3) signaling pathway. Although the detailed mechanism by which midazolam acts on cancer cells remains elusive, the results described above suggest that midazolam could present a potential therapeutic in various cancers. Further study into the role of midazolam in the prevention of cancer is crucial if translation from the laboratory to the clinical setting can occur.

\section{Conflicts of Interest}

The authors declare no conflicts of interest.

\section{Acknowledgments}

Many thanks to Dr. Sharon Forsyth in Biomedical Editing International in Australia for his assistance in this work. This work was supported by Science and Technology Fund Project of Shenyang Medical College (no. 20142034).

\section{References}

[1] N. Stefan, H. U. Häring, F. B. Hu, and M. B. Schulze, "Divergent associations of height with cardiometabolic disease and cancer: epidemiology, pathophysiology, and global implications," The Lancet Diabetes \& Endocrinology, vol. 4, no. 5, pp. 457-467, 2016.

[2] G. L. Snyder and S. Greenberg, "Effect of anaesthetic technique and other perioperative factors on cancer recurrence," British Journal of Anaesthesia, vol. 105, no. 2, pp. 106-115, 2010. 
[3] F. Desmond, N. Mulligan, M. Stokes, and D. J. Buggy, "Effect of anaesthetic technique on immune cell infiltration in breast cancer: a follow-up pilot analysis of a prospective, randomised, investigator-masked study," Anticancer Research, vol. 35, no. 3, pp. 1311-1320, 2015.

[4] N. Kocak, F. Ozen, I. H. Yildirim, and Y. Duran, "Fentanyl inhibits tumorigenesis from human breast stem cells by inducing apoptosis," Asian Pacific Journal of Cancer Prevention, vol. 18, no. 3, pp. 735-739, 2017.

[5] F. Zhang, T. Ding, L. Yu, Y. Zhong, H. Dai, and M. Yan, "Dexmedetomidine protects against oxygen-glucose deprivation-induced injury through the I2 imidazoline receptorPI3K/AKT pathway in rat C6 glioma cells," Journal of Pharmacy and Pharmacology, vol. 64, no. 1, pp. 120-127, 2012.

[6] K. Tanabe, S. Takai, R. Matsushima-Nishiwaki, K. Kato, S. Dohi, and $\mathrm{O}$. Kozawa, " $\alpha 2$ ad re no receptor agonist regulates protein kinase C-induced heat shock protein 27 phosphorylation in C6 glioma cells," Journal of Neurochemistry, vol. 106, no. 2, pp. 519528, 2008.

[7] M. Álvaro-Bartolomé and J. A. García-Sevilla, "The neuroplastic index p-FADD/FADD and phosphoprotein PEA-15, interacting at GABAA receptor, are upregulated in brain cortex during midazolam-induced hypnosis in mice," European Neuropsychopharmacology, vol. 25, no. 11, pp. 2131-2144, 2015.

[8] D. I. Obradović, M. M. Savić, M. M. Obradović, N. D. Ugrešić, and D. R. Bokonjić, "The lack of bicuculline and picrotoxin influence on midazolam depressant action on brain oxygen consumption," Neuroscience Letters, vol. 397, no. 3, pp. 201-204, 2006.

[9] A. Shahriari, M. Khooshideh, and M. H. Heidari, "Prevention of nausea and vomiting in caesarean section under spinal anaesthesia with midazolam or metoclopramide?" Journal of the Pakistan Medical Association, vol. 59, no. 11, pp. 756-759, 2009.

[10] A. Sen, A. Rudra, S. K. Sarkar, and B. Biswas, "Intrathecal midazolam for postoperative pain relief in caesarean section delivery," Journal of the Indian Medical Association, vol. 99, no. 12, pp. 683-686, 2001.

[11] J. S. Barrett, D. Patel, E. Dombrowsky, G. Bajaj, and J. M. Skolnik, "Risk assessment of drug interaction potential and concomitant dosing pattern on targeted toxicities in pediatric cancer patients," AAPS Journal, vol. 15, no. 3, pp. 775-786, 2013.

[12] M. F. Stevens, R. Werdehausen, N. Gaza et al., "Midazolam activates the intrinsic pathway of apoptosis independent of benzodiazepine and death receptor signaling," Regional Anesthesia and Pain Medicine, vol. 36, no. 4, pp. 343-349, 2011.

[13] B. Sinner, O. Friedrich, Y. Zausig, T. Bein, and B. M. Graf, "Toxic effects of midazolam on differentiating neurons in vitro as a consequence of suppressed neuronal Ca2+-oscillations," Toxicology, vol. 290, no. 1, pp. 96-101, 2011.

[14] C. Young, V. Jevtovic-Todorovic, Y.-Q. Qin et al., "Potential of ketamine and midazolam, individually or in combination, to induce apoptotic neurodegeneration in the infant mouse brain," British Journal of Pharmacology, vol. 146, no. 2, pp. 189-197, 2005.

[15] S. Erdine, A. Yücel, S. Özyalçin et al., "Neurotoxicity of midazolam in the rabbit," Pain, vol. 80, no. 1-2, pp. 419-423, 1999.

[16] L. Glynn, "A critical appraisal tool for library and information research," Library Hi Tech, vol. 24, no. 3, pp. 387-399, 2006.

[17] M. Martina, M. Clerici, V. Baldo, D. Bonetti, G. Lucchini, and M. P. Longhese, "A balance between Tell and Rif2 activities regulates nucleolytic processing and elongation at telomeres,"
Molecular and Cellular Biology, vol. 32, no. 9, pp. 1604-1617, 2012.

[18] P. Rovere-Querini, S. Brunelli, E. Clementi, and A. A. Manfredi, "Cell death: tipping the balance of autoimmunity and tissue repair," Current Pharmaceutical Design, vol. 14, no. 3, pp. 269277, 2008.

[19] Y. S. Cho, S. Y. Park, H. S. Shin, and F. K.-M. Chan, "Physiological consequences of programmed necrosis, an alternative form of cell demise," Molecules and cells, vol. 29, no. 4, pp. 327-332, 2010.

[20] M. S. Ola, M. Nawaz, and H. Ahsan, "Role of Bcl-2 family proteins and caspases in the regulation of apoptosis," Molecular and Cellular Biochemistry, vol. 351, no. 1-2, pp. 41-58, 2011.

[21] V. Yanamadala, H. Negoro, and B. M. Denker, "Heterotrimeric $G$ proteins and apoptosis: Intersecting signaling pathways leading to context dependent phenotypes," Current Molecular Medicine, vol. 9, no. 5, pp. 527-545, 2009.

[22] Y. Kawarazaki, H. Ichijo, and I. Naguro, "Apoptosis signalregulating kinase 1 as a therapeutic target," Expert Opinion on Therapeutic Targets, vol. 18, no. 6, pp. 651-664, 2014.

[23] V. Jendrossek, "The intrinsic apoptosis pathways as a target in anticancer therapy," Current Pharmaceutical Biotechnology, vol. 13, no. 8, pp. 1426-1438, 2012.

[24] A. Fleischer, A. Ghadiri, F. Dessauge et al., "Modulating apoptosis as a target for effective therapy," Molecular Immunology, vol. 43, no. 8, pp. 1065-1079, 2006.

[25] J. J. Alam, "Apoptosis: target for novel drugs," Trends in Biotechnology, vol. 21, no. 11, pp. 479-483, 2003.

[26] S. Kasibhatla and B. Tseng, "Why target apoptosis in cancer treatment?" Molecular Cancer Therapeutics, vol. 2, no. 6, pp. 573-580, 2003.

[27] Y. Tang, W. Zhan, T. Cao et al., "CacyBP/SIP inhibits Doxourbicin-induced apoptosis of glioma cells due to activation of ERK1/2," IUBMB Life, vol. 68, no. 3, pp. 211-219, 2016.

[28] N. K. Mak, Y. Y. Szeto, M. C. Fung, K. N. Leung, and S. K. Kwan, "Effects of midazolam on the differentiation of murine myeloid leukemia cells," Chemotherapy, vol. 43, no. 4, pp. 272-281, 1997.

[29] E. C. So, Y.-X. Lin, C. H. Tseng et al., "Midazolam induces apoptosis in MA-10 mouse leydig tumor cells through caspase activation and the involvement of MAPK signaling pathway," OncoTargets and Therapy, vol. 7, pp. 211-221, 2014.

[30] S. Ohno, K. Kobayashi, S. Uchida, O. Amano, H. Sakagami, and H. Nagasaka, "Cytotoxicity and type of cell death induced by midazolam in human oral normal and tumor cells," Anticancer Research, vol. 32, no. 11, pp. 4737-4747, 2012.

[31] E. C. So, Y.-C. Chen, S.-C. Wang et al., "Midazolam regulated caspase pathway, endoplasmic reticulum stress, autophagy, and cell cycle to induce apoptosis in MA-10 mouse leydig tumor cells," OncoTargets and Therapy, vol. 9, pp. 2519-2533, 2016.

[32] S. Braun, I. Bauer, B. Pannen, and R. Werdehausen, "Pretreatment but not subsequent coincubation with midazolam reduces the cytotoxicity of temozolomide in neuroblastoma cells," BMC Anesthesiology, vol. 15, article 151, 2015.

[33] Y.-L. Dou, J.-P. Lin, F.-E. Liu et al., "Midazolam inhibits the proliferation of human head and neck squamous carcinoma cells by downregulating p300 expression," Tumor Biology, vol. 35, no. 8, pp. 7499-7504, 2014.

[34] Y. Dou, Y. Li, J. Chen et al., "Inhibition of cancer cell proliferation by midazolam by targeting transient receptor potential melastatin 7," Oncology Letters, vol. 5, no. 3, pp. 1010-1016, 2013. 
[35] S. K. Mishra, J.-H. Kang, C. W. Lee et al., "Midazolam induces cellular apoptosis in human cancer cells and inhibits tumor growth in xenograft mice," Molecules and Cells, vol. 36, no. 3, pp. 219-226, 2013.

[36] J. Chen, Y. Dou, X. Zheng et al., “TRPM7 channel inhibition mediates midazolam-induced proliferation loss in human malignant glioma," Tumor Biology, vol. 37, no. 11, pp. 1472114731, 2016.

[37] J.-Q. Hong, S.-H. Wu, Z.-Y. Chen, W.-H. Zhuang, and H.-Z. Gao, "Effect of midazolam on mantle cell lymphoma JeKo-1 cell line and its relevant mechanisms," Journal of experimental hematology/Chinese Association of Pathophysiology, vol. 21, no. 6, pp. 1460-1463, 2013.

[38] Y. L. Dou, W. F. Liu, L. Y. Wang, and H. H. Shu, "Midazolam downregulat USP22 and inhibit the proliferation of human colon cancer SW480 cells," Journal of Digestive Oncology (Electronic Version), vol. 4, no. 4, pp. 260-264, 2012.

[39] H. Wang, Z. Liu, Y. Gou et al., "Apoptosis and necrosis induced by novel realgar quantum dots in human endometrial cancer cells via endoplasmic reticulum stress signaling pathway," International Journal of Nanomedicine, vol. 10, pp. 5505-5512, 2015.

[40] J.-J. Lin, R. Y. L. Wang, J.-C. Chen, C.-C. Chiu, M.-H. Liao, and Y.-J. Wu, "Cytotoxicity of 11-epi-sinulariolide acetate isolated from cultured soft corals on HA22T cells through the endoplasmic reticulum stress pathway and mitochondrial dysfunction," International Journal of Molecular Sciences, vol. 17, no. 11, article 1787, 2016.

[41] Y.-J. Lin, S.-F. Peng, M.-L. Lin et al., "Tetrandrine induces apoptosis of human nasopharyngeal carcinoma npc-Tw 076 cells through reactive oxygen species accompanied by an endoplasmic reticulum stress signaling pathway," Molecules, vol. 21, no. 10, article 1353, 2016.

[42] Z. Ren, S. Chen, J. Zhang, U. Doshi, A. P. Li, and L. Guo, "Endoplasmic reticulum stress induction and ERK1/2 activation contribute to nefazodone-induced toxicity in hepatic cells," Toxicological Sciences, vol. 154, no. 2, pp. 368-380, 2016.

[43] W. B'Chir, A.-C. Maurin, V. Carraro et al., "The eIF2 $\alpha /$ ATF4 pathway is essential for stress-induced autophagy gene expression," Nucleic Acids Research, vol. 41, no. 16, pp. 7683-7699, 2013.

[44] J. Martinou and R. J. Youle, "Mitochondria in apoptosis: Bcl-2 family members and mitochondrial dynamics," Developmental Cell, vol. 21, no. 1, pp. 92-101, 2011.

[45] S. Cory and J. M. Adams, "The BCL2 family: regulators of the cellular life-or-death switch," Nature Reviews Cancer, vol. 2, no. 9, pp. 647-656, 2002.

[46] T. Lindsten, A. J. Ross, A. King et al., "The combined functions of proapoptotic Bcl-2 family members Bak and Bax are essential for normal development of multiple tissues," Molecular Cell, vol. 6, no. 6, pp. 1389-1399, 2000.

[47] K. Shiraishi, M. Oku, K. Kawaguchi, D. Uchida, H. Yurimoto, and Y. Sakai, "Yeast nitrogen utilization in the phyllosphere during plant lifespan under regulation of autophagy," Scientific Reports, vol. 5, article 9719, 2015.

[48] Y.-H. Teng, J.-P. Li, S.-L. Liu et al., "Autophagy protects from raddeanin A-induced apoptosis in SGC-7901 human gastric cancer cells," Evidence-based Complementary and Alternative Medicine, vol. 2016, Article ID 9406758, 8 pages, 2016.

[49] X. Peng, S. Bai, X. Ding, and K. Zhang, "Pathological impairment, cell cycle arrest and apoptosis of thymus and bursa of fabricius induced by aflatoxin-contaminated corn in Broilers," International Journal of Environmental Research and Public Health, vol. 14, no. 1, article 77, 2017.
[50] P. Pozarowski and Z. Darzynkiewicz, "Analysis of cell cycle by flow cytometry," Methods in Molecular Biology, vol. 281, pp. 301311, 2004.

[51] G. I. Evan and K. H. Vousden, "Proliferation, cell cycle and apoptosis in cancer," Nature, vol. 411, no. 6835, pp. 342-348, 2001.

[52] D. C. Bedford, L. H. Kasper, T. Fukuyama, and P. K. Brindle, "Target gene context influences the transcriptional requirement for the KAT3 family of CBP and p300 histone acetyltransferases," Epigenetics, vol. 5, no. 1, pp. 9-15, 2010.

[53] R. B. Selvi, A. Swaminathan, S. Chatterjee et al., "Inhibition of p300 Lysine Acetyltransferase activity by Luteolin reduces tumor growth in head and neck squamous cell carcinoma (HNSCC) xenograft mouse model," Oncotarget, vol. 6, no. 41, pp. 43806-43818, 2015.

[54] M. M. Wong, J. S. Byun, M. Sacta, Q. Jin, S. Baek, and K. Gardner, "Promoter-bound p300 complexes facilitate postmitotic transmission of transcriptional memory," PLoS ONE, vol. 9, no. 6, Article ID e99989, 2014.

[55] J. Jiang, M.-H. Li, K. Inoue, X.-P. Chu, J. Seeds, and Z.-G. Xiong, "Transient receptor potential melastatin 7-like current in human head and neck carcinoma cells: role in cell proliferation," Cancer Research, vol. 67, no. 22, pp. 10929-10938, 2007. 


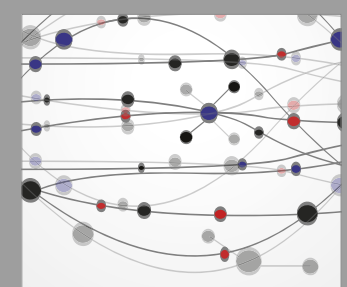

The Scientific World Journal
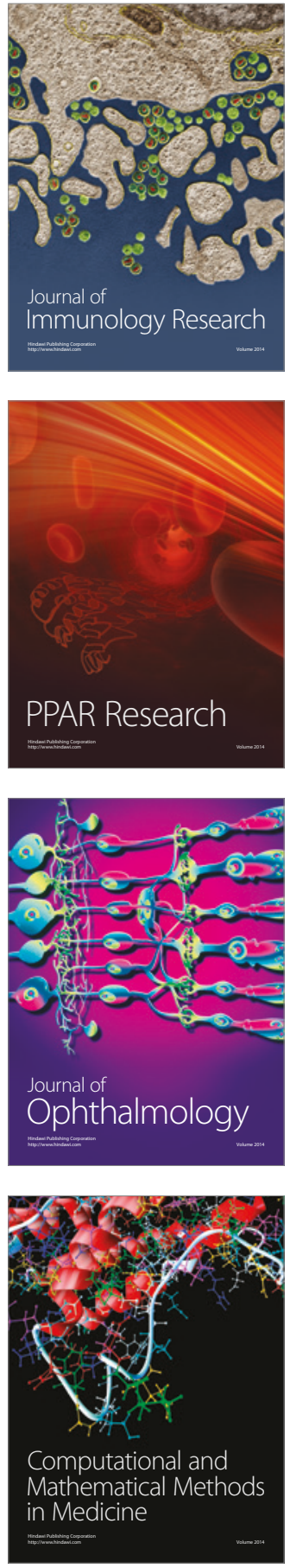

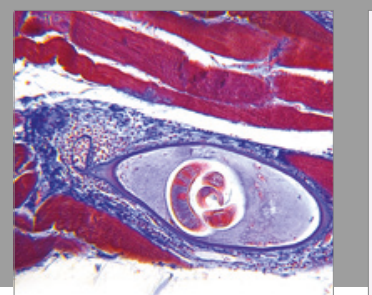

Gastroenterology Research and Practice
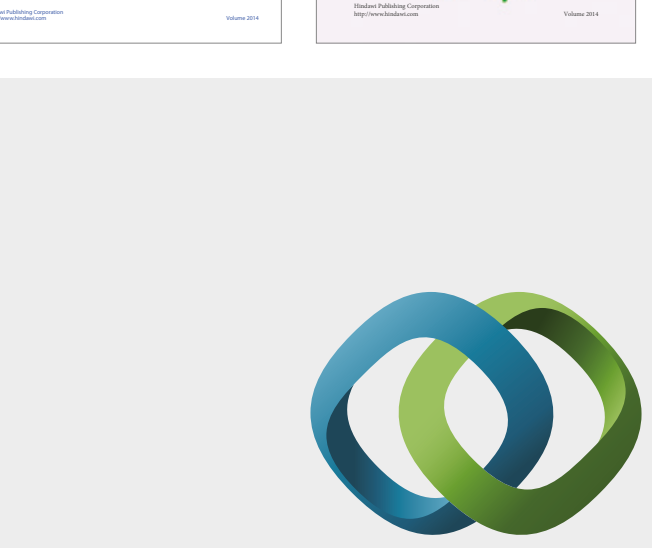

\section{Hindawi}

Submit your manuscripts at

https://www.hindawi.com
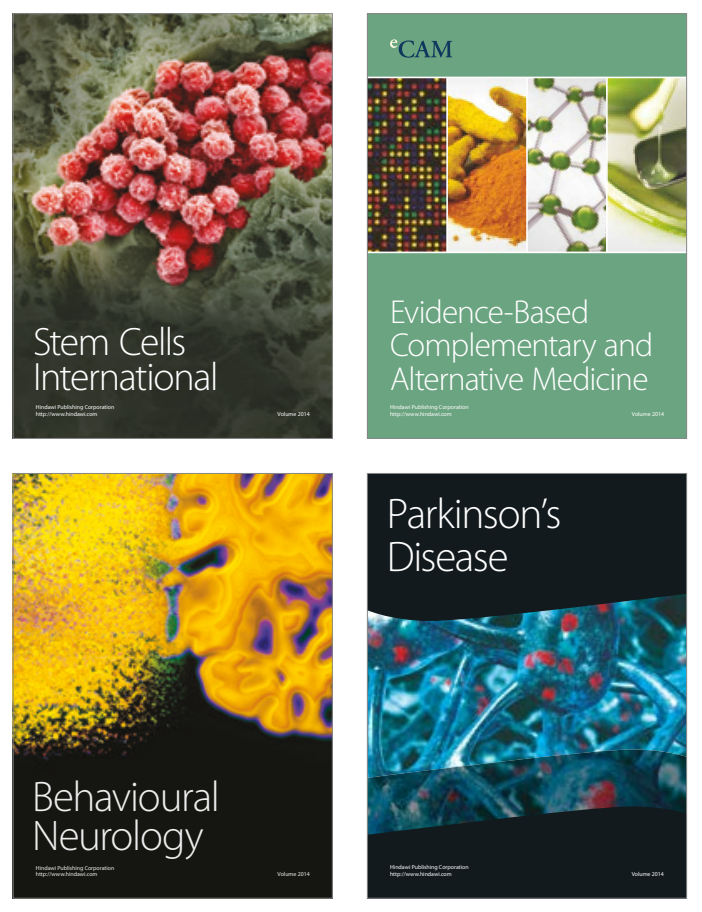
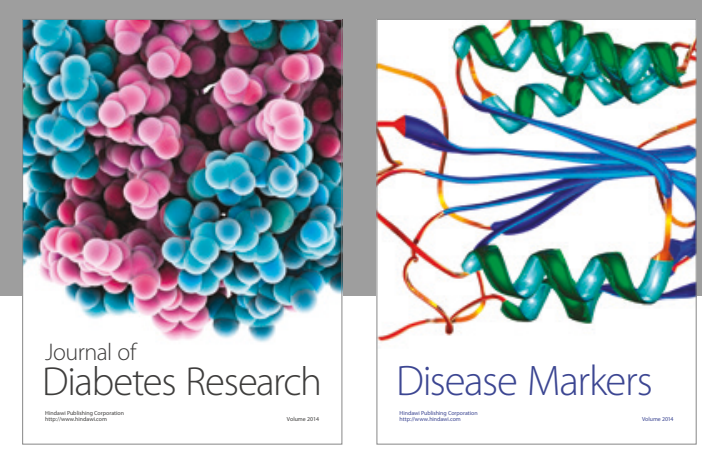

Disease Markers
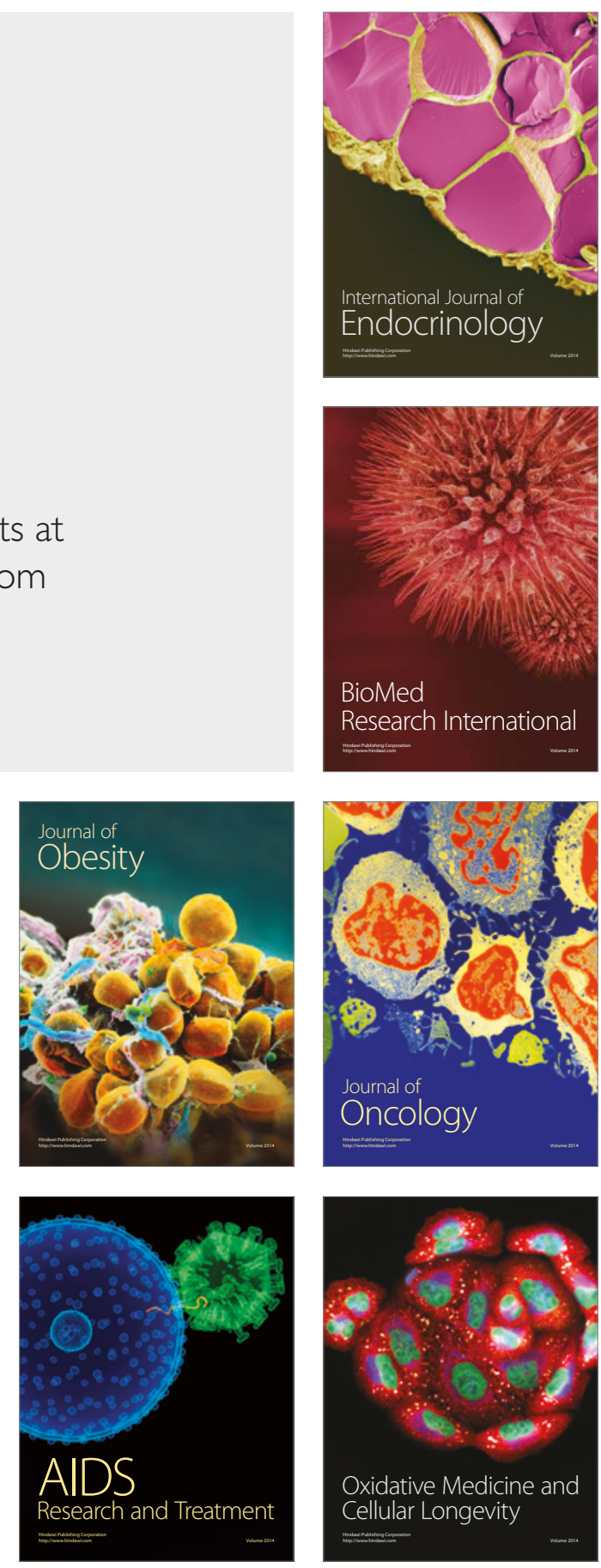